\title{
A FLORICAULA/LEAFY gene homolog is preferentially expressed in developing female cones of the tropical pine Pinus caribaea var. caribaea
}

\author{
Marcelo Carnier Dornelas and Adriana Pinheiro Martinelli Rodriguez \\ Universidade de São Paulo, Centro de Energia Nuclear na Agricultura, Laboratório de Biotecnologia \\ Vegetal, Piracicaba, SP, Brazil.
}

\begin{abstract}
In angiosperms, flower formation is controlled by meristem identity genes, one of which, FLORICAULA $(F L O) / L E A F Y(L F Y)$, plays a central role. It is not known if the formation of reproductive organs of pre-angiosperm species is similarly regulated. Here, we report the cloning of a conifer (Pinus caribaea var. caribaea) FLO/LFY homolog, named PCLFY. This gene has a large $\mathrm{C}$-terminal region of high similarity to angiosperm $F L O / L F Y$ orthologs and shorter regions of local similarity. In contrast to angiosperms, conifers have two divergent genes resembling LFY. Gymnosperm FLO/LFY proteins constitute a separate clade, that can be divided into two divergent groups. Phylogenetic analysis of deduced protein sequences has shown that $P C L F Y$ belongs to the $L F Y$-like clade. Northern hybridization analysis has revealed that $P C L F Y$ is preferentially expressed in developing female cones but not in developing male cones. This expression pattern was confirmed by in situ hybridization and is consistent with the hypothesis of PCLFY being involved in the determination of the female cone identity. Additionally, mutant complementation experiments have shown that the expression of the PCLFY coding region, driven by the Arabidopsis $L F Y$ promoter, can confer the wild-type phenotype to Ify-26 transgenic mutants, suggesting that both gymnosperm and angiosperm $L F Y$ homologs share the same biological role.
\end{abstract}

Key words: $L E A F Y$, plant reproduction, development, gene expression, flowering.

Received: May 31, 2004; Accepted: February 15, 2005.

\section{Introduction}

The molecular mechanisms underlying both intrinsic and extrinsic controls of pine shoot development are largely unknown. For both practical and scientific reasons, we are interested in mechanisms that bring about the formation of reproductive organs rather than vegetative shoots. The practical goal is to control flowering in this commercially important tropical forestry species. The knowledge of fundamental aspects of the reproductive development will allow us to genetically modify this process and to produce trees that flower earlier or are sterile. Genetic engineering of tropical pine, including regeneration of transgenic plants, has already been achieved (Walter et al., 1998). A further scientific goal is to uncover the regulation of reproduction in pre-angiosperm species and gain understanding of the evolution of this process in plants.

Several genes involved in the vegetative-toreproductive transition have been cloned in angiosperm annual species (Levy and Dean, 1998; Lohmann and Weigel,

Send correspondence to M.C. Dornelas. Universidade de São Paulo, Centro de Energia Nuclear na Agricultura. Laboratório de Biotecnologia Vegetal, Av. Centenário 303, 13400-970 Piracicaba, SP, Brazil. E-mail: mcdornel@ cena.usp.br.
2002; Izawa et al., 2003). These genes can be loosely classified into one of the following three groups: (i) flowering-time genes that are involved in the vegetative-toreproductive phase change by acting globally or locally in the shoot apical meristem; (ii) locally acting meristem identity genes that regulate the establishment of the floral meristem identity; and (iii) locally acting floral organ identity genes that regulate the identity of floral organs. These genes and their functions appear to be conserved in angiosperms, including monocotyledons (An et al., 1994; Pnuelli et al., 1994; Colombo et al., 1996; Mena et al., 1996). In contrast, there is very little information concerning preangiosperm plant species, in which only a few corresponding genes have been cloned (Picea abies, Tandre et al., 1995; Gnetum gnemon, Münster et al., 1997; Pinus radiata, Mouradov et al., 1998; Pinus radiata, Mellerowicz et al., 1998). The LEAFY (LFY) gene of Arabidopsis, or its Antirrhinum ortholog FLORICAULA (FLO), is one of the key regulatory genes involved in both the control of the vegetative-to-reproductive phase change (Blázquez et al., 1997 ) and the acquisition by axillary meristems of the floral meristem identity (Huala and Sussex, 1992; Weigel et al., 1992; Weigel and Nilsson, 1995). Plants overexpressing 
$L F Y$ flower early, produce flowers in the place of lateral vegetative shoots and convert their otherwise indeterminate terminal shoot meristems to flowers (Weigel and Nilsson, 1995; Blázquez et al., 1997). These effects can also be observed in heterologous angiosperm species (Nilsson and Weigel, 1997), indicating that the function of $L F Y$ is largely conserved. Mutations in FLO/LFY cause the conversion of flowers into shoots. In Arabidopsis, male-sterile flowers are occasionally produced even in mutants homozygous for the strongest lfy alleles, indicating that a parallel pathway may specify floral meristem identity. In contrast, in Antirrhinum, mutations in FLO abolish flowering (Coen et al., 1990). Thus, the activity of the parallel pathway specifying floral meristem identity can vary among species. This paper reports cloning and expression studies of a Pinus caribaea var. caribaea FLO/LFY homolog named PcLFY. In Pinus, genes NEEDLY (NLY) and PRFLL were reported, representing two divergent Pinus radiata LFY homologs (Mouradov et al., 1998; Mellerowicz et al., 1998). Sequence comparisons indicate that PRFLL and NLY represent divergent proteins, and that conifers, in contrast to angiosperms, have two $L F Y$-like paralogs. PRFLL is largely expressed in buds and male cones but not in female cones or other somatic tissues, while $N L Y$ is preferentially expressed in female cones (Mouradov et al., 1998; Mellerowicz et al., 1998). We performed a detailed spatial and temporal analysis of the $P$. caribaea PcLFY gene, using Northern and in situ hybridization analysis, and our results were consistent with PcLFY being involved in female cone identity determination. Additionally, our experiments demonstrated that PCLFY can complement the lfy-26 Arabidopsis mutant, which shows the strongest mutant phenotype, suggesting that both pine and Arabidopsis LFY homologs may share the same biological role.

\section{Material and Methods}

\section{Plant material}

Material for genomic DNA and RNA extraction and for microscopy of vegetative and reproductive tissues of Pinus caribaea var. caribaea was collected in the fields of Escola Superior de Agricultura Luiz de Queiroz, of the University of São Paulo (Piracicaba, SP, Brazil). Young expanding needles were collected for the extraction of genomic DNA. RNA-blot, in situ hybridization and SEM analyses were performed on plant tissues collected and fixed at different developmental stages during two growing seasons corresponding to the years 2000 to 2003 .

\section{DNA and RNA extraction, library construction and gene cloning}

Total RNA for cDNA library construction and Northern experiments was isolated from young pine leaves (needles), vegetative apices, developing male and female cones at different developmental stages and roots of recently ger- minated seeds (germinated on wet paper in the dark for 4 days), using the RNeasy plant Minikit (QIAGEN) according to the manufacturer's instructions. Genomic DNA for PCR amplification, Southern analysis and construction of genomic libraries was isolated by the traditional CTABbased method (Sambrook et al., 1989).

The genomic clones of PcLFY were isolated by screening 300,000 plaques from a $P$. caribaea genomic library $\left(76 \times 10^{-6} \mathrm{pfu}\right)$ constructed with partially Sau3Adigested genomic DNA, using the Packagene Lambda Packing Systems (Promega). This screening was performed with a biotin-labeled probe (North2South chemiluminescent system, Pierce), using the entire Arabidopsis $L F Y$ cDNA from plasmid pDW124 (Weigel et al., 1992) as template. Two adjacent BamHI fragments (P45B with 3.35 $\mathrm{kbp}$, and $\mathrm{P} 65 \mathrm{~B}$ with $6.4 \mathrm{kbp}$ ) containing the genomic PCLFY sequence were subcloned into pBluescriptKS (Clontech). Subclones were prepared by nested deletions (as described by Zhu and Clark, 1995) and sequenced on an ABI Prism 377 automated sequencer (Perkin-Elmer/Applied Biosystems), using the DYEnamic ET terminator Cycle Sequencing Kit (Amersham/ Pharmacia Biotech, USA) coupled with M13 reverse and forward primers according to the manufacturer's instructions. The complete PcLFY genomic sequence was deposited in the GenBank under the accession number AY640315.

A cDNA library was constructed using total RNA from a mix of male and female cones at different developmental stages. The poly-A fraction RNA was isolated (Sussman et al., 2000), and the first strand of cDNA was synthesized using the SuperScript cloning system (Life Technologies). The cDNA library screening was performed using a PCR-based strategy (Sussman et al., 2000) and the $L F Y$-specific degenerated primers L1: 5'-CGGAY ATIAAYAARCCIAARATGMGICAYTA-3' and L4: 5'-C GGATCCGTGICK-IARIYKIGTIGGIACRTA-3' (Frohlich and Meyerowitz, 1997). The insert sizes of the positive clones were determined by PCR using the M13 forward and reverse primers, and the five positive clones were sequenced on both strands. The longest PcLFY cDNA sequence was deposited in the GenBank under the accession number AY640316.

\section{Southern and Northern hybridization}

Southern blotting was performed as described in Sambrook et al. (1989), using genomic DNA digested with XhoI and PstI and blotted on a Hybond-N Plus membrane (Amersham). Northern experiments were performed using $10 \mu \mathrm{g}$ of total RNA extracted from male and female developing cones (a mix of different developmental stages), vegetative apices and young needles, separated in a denaturating agarose gel (Sambrook et al., 1989) and hybridized to a $P C L F Y$ probe.

The $P C L F Y$ probe used in both Southern and Northern experiments was a $235 \mathrm{bp}$ PCR product obtained from the 3 ' 
transcribed region of the gene, using the primers P13: 5'-CTCCAAGTGACAGAGCTGACG-3' and P25: 5'-CT GCTGGATGTGCAACAT-3', and a PCLFY cDNA clone as template. PCR reactions were performed in a final volume of $25 \mu \mathrm{L}$ with an initial 3 min denaturation cycle at $96{ }^{\circ} \mathrm{C}$, followed by 40 cycles of $96{ }^{\circ} \mathrm{C}$ for $40 \mathrm{~s} ; 45^{\circ} \mathrm{C}$ for $30 \mathrm{~s}$, and $72^{\circ} \mathrm{C}$ for $2 \mathrm{~min}$. The PCR product was purified using the CONCERT Rapid PCR Purification System (Gibco-Life Sciences). The probe was labeled with fluorescein, using the DCP-Star GeneImage System (Pharmacia-Amersham). Hybridization conditions, washing stringencies and detection were those suggested by the kit manufacturer. As a control for gel loading in Northern experiments, the stripped membrane was re-hybridized with a heterologous probe for a constitutively expressed gene, under low stringency, using cDNA for an Arabidopsis ubiquitin as template (GenBank accession AB5432).

\section{In situ hybridization}

Preparation of slides, digoxigenin-labeling of RNA probes, and hybridization were performed as described elsewhere (Dornelas et al., 1999; 2000). A high-stringency hybridization condition was achieved using $50 \%$ formamide in the hybridization solution and washes with up to $0.1 \% \mathrm{SSC}$ at $55^{\circ} \mathrm{C}$. The template for the $P C L F Y$ digoxigenin-labeled probe was the $1,498 \mathrm{bp}$ cDNA fragment containing the complete coding region, cloned in pGEM-T vector. The hybridized sections were viewed immediately and photographed under a Zeiss Axiovert 35 microscope.

\section{Microscopy}

All plant material collected for microscopy was immediately fixed in $4 \%$ paraformaldehyde under vacuum for $24 \mathrm{~h}$ and dehydrated to absolute ethanol, where it was stored at $4{ }^{\circ} \mathrm{C}$ until needed. For light microscopy, the dehydrated samples were embedded in Historesin (Leica, 2hydroxyethyl-methacrylate). Resin polymerization was carried out at room temperature for $48 \mathrm{~h}$. After polymerization, serial sections of 5-8 $\mu \mathrm{m}$ were obtained and stained with $0.05 \%$ toluidine blue (Dornelas et al., 1992). The histological sections were observed and photographed under a Zeiss Axiovert 35 microscope.

Alternatively, the plant material was initially dissected in absolute ethanol under an Olympus dissecting microscope. The resultant material was critical point-dried with $\mathrm{CO}_{2}$ in a Balzer's drier and further dissected, when necessary. The samples were mounted in metallic stubs with carbon conductive adhesive tape, coated with colloidal gold and observed at 10-20 kV using a ZEISS DSM 940 A or a LEO 435 VP scanning electron microscope.

\section{Sequence comparisons}

The partial PCLFY sequences obtained were manipulated in a standard word processor and aligned using
ClustalW (Thompson et al., 1994), before being checked for similarity with sequences already deposited in public databases, using BLASTX (Altschul et al., 1997). The complete nucleotide and protein sequences of different $L F Y$ homologs were retrieved from GenBank (http://www.ncbi.nlm.nih.gov/entrez/query.fcgi) and aligned with the entire nucleotide and deduced protein sequences of PcLFY, using ClustalW (Thompson et al., 1994). Distance matrixes were obtained from the alignments, and comparative trees were built using TreeView (Page, 2000). Alternatively, parsimony analysis was performed using PAUP (Swofford, 1998).

\section{Complementation of the Arabidopsis Ify-26 mutant}

The XbaI-SmaI PcLFY fragment, carrying the coding region of $P C L F Y$, with its endogenous start and stop codons, was obtained from plasmid pPCLFY and bluntended using DNA polymerase I (Klenow fragment). An intermediate $\mathrm{pDW} 132 \mathrm{P}$ vector was prepared by cloning the polished fragment described above into the SmaI site of pDW132, containing the Arabidopsis LFY promoter (a gift from D. Weigel, Salk Institute, LA Jolla CA, USA). The correct orientation of the cloning process was checked by endonuclease digestion. The Pst I-SpeI fragment from the resultant $\mathrm{pDW} 132 \mathrm{P}(L F Y: \because P C L F Y)$ vector was blunt-ended with Klenow and cloned into the plant transformation vector pSKI015 (a gift from D. Weigel, Salk Institute, LA Jolla CA, USA), that contains the bar gene, allowing selection with the herbicide Basta (Sylvet), constituting the pSKI015P vector. Arabidopsis plants (Columbia ecotype) transgenic for pSKI015E T-DNA were generated by using Agrobacterium tumefaciens-mediated in planta transformation, as described by Bechtold and Pelletier (1998). Putatively transformed seeds were selected upon germination on sand wetted with a Basta (Sylvet) solution at $500 \mu \mathrm{L} . \mathrm{mL}^{-1}$. Homozygous (Basta-resistant) lines were created by selfing. The resistant:sensitive segregation ratio was used to estimate the number of transformed T-DNA loci. T2 lines, homozygous for the $L F Y:$ PcLFY T-DNA loci, were identified by sowing 200-300 T2 seeds, derived from different $\mathrm{T} 1$ plants under selective conditions. Transgenic and non-transgenic plants were grown in growth chambers at $23{ }^{\circ} \mathrm{C}$ under illumination with fluorescent light: long-day (LD) conditions (16 h of light/8 h of darkness) or short-day (SD) conditions ( $8 \mathrm{~h}$ of light/16 h of darkness). Finally, $L F Y:: P c L F Y$ transformants in the Columbia ecotype were crossed to the strong lfy-26 mutant allele in the Landsberg erecta background (wild-type and mutant Arabidopsis seeds were obtained from the ABRC seed stock at the Ohio State University facility at Columbus, Ohio, USA). To genotype F2 plants at the $L F Y$ locus, CAPS (Cleared Amplified Polymorphic Sequences; Konieczny and Ausubel, 1993) markers that distinguished between Columbia and Landsberg were used (URL: http:// www.salk.eduyLABSypbio-wycaps.html). Transgenic and 
non-transgenic Arabidopsis flowers and inflorescences at different developmental stages were photographed under a stereomicroscope or analyzed by SEM.

\section{Results}

\section{Shoot and female cone development in Pinus caribaea var. caribaea}

Vegetative and reproductive development in Pinus species is regulated by an integrated system of ontogenetic, positional and environmental factors. These factors determine the rate of formation, the type and the differentiation of primordia produced at the flanks of the apical meristem and in axils (Doak, 1935). In the juvenile stage, the meristem continuously produces primary needle primordia that elongate and form photosynthetic organs (Figure 1A). Some of the primary needle primordia are accompanied by axillary meristems that form either long or short shoot primordia (Riding, 1972). Long shoot primordia give rise to branches, whereas short shoot primordia form secondary needles while their apical meristems cease to function. As pine seedlings pass into the adult stage, the primary needles shorten and develop into scale-like cataphylls (Doak, 1935). Some cataphylls become bud scales, enclosing both apical and axillary meristems together with associated primordia and forming closed buds (Figure 1B and E). Bud growth becomes cyclic, with sequential formation of various types of primordia within each cycle. The number of cycles produced annually and bud morphology vary among pine species (Doak, 1935). The apical meristem produces bud scales and bracts subtending axillary short and long shoot primordia (Figure 1B and E). In addition, two new kinds of axillary primordia are formed: the male and female cone primordia. Male cone primordia usually develop in buds on subordinate branches located within the lower crown. These buds produce only one growth cycle during a year. Female cone primordia develop in buds on dominant branches located within the upper crown. These buds produce up to five growth cycles each year (Doak, 1935). Typically, female cones (Figure 1D and F) are found in the first two cycles initiated in the summer (Bollman, 1983). During each cycle, the meristem produces primordia in a defined sequence (Doak, 1935). Male and female cone primordia are not present in all buds, indicating that the formation of reproductive primordia in mature plants is regulated by some other factors, in addition to the ontogenetic stage and position. These factors probably include environment and gibberellins (Cecich et al., 1994).

\section{Cloning and sequence analysis}

Primary screening of 15,000 cDNA clones of a $P$. caribaea var. caribaea reproductive tissue library using a PCR approach (Sussman et al., 2000) identified five positive clones that were sequenced on both strands. All the five clones contained inserts of over $1.5 \mathrm{~kb}$, with identical open
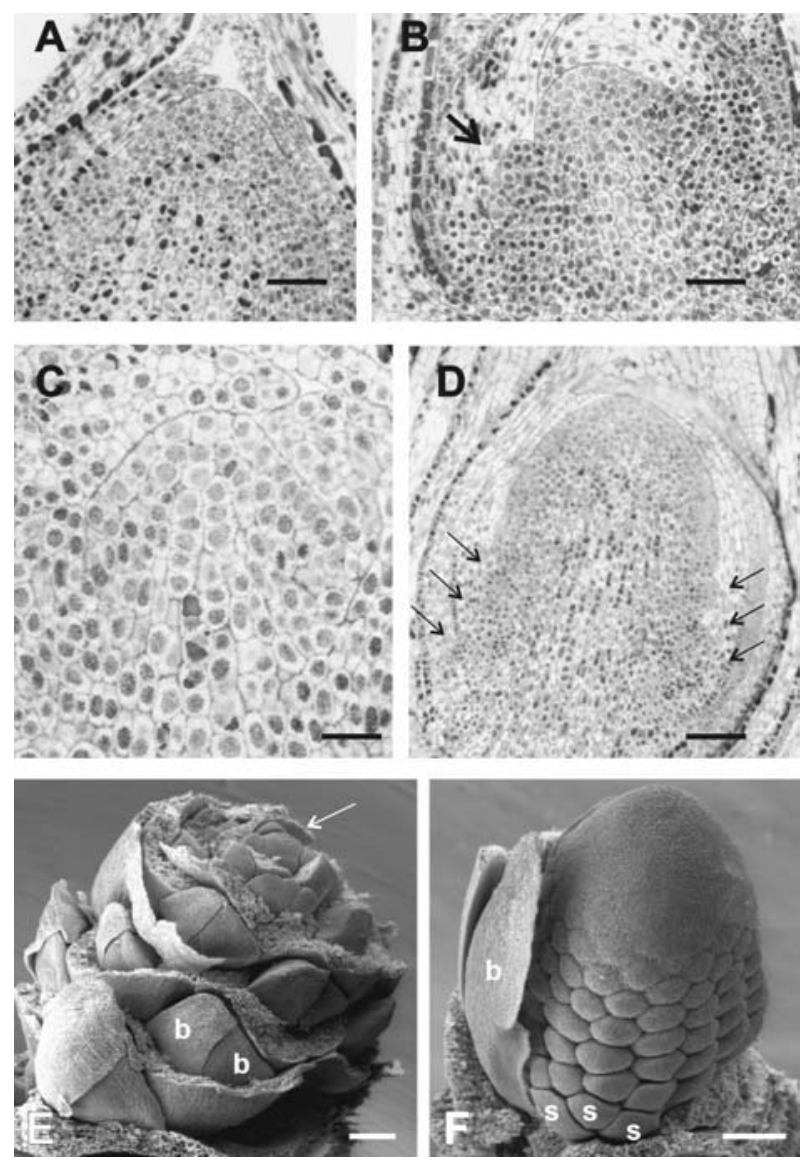

Figure 1 - P. caribaea var. caribaea vegetative and reproductive meristem development. A-D: Toluidine blue-stained longitudinal sections. E and F: SEM. Apical vegetative meristem of a juvenile (1 year-old) plant. B: Apical meristem of an adult (15 year-old) plant. The arrow indicates a lateral meristem. C: Early-developing female cone. The oviliferous scale primordial still not visible. D: Developing female cone at the onset of the oviliferous scales (arrows) E: Long-shoot apex of an adult (15 year-old) plant. The arrow points to the terminal meristem. Bracts (b) cover and protect the subordinate branch lateral meristems. F: Developing female cone at the onset of the oviliferous scales, at approximately the same stage as that shown in D. b: bract primordium s: oviliferous scale primordium. Bars: A and B: $150 \mu \mathrm{m}$; : $100 \mu \mathrm{m}$; D and F: $200 \mu \mathrm{m}$.

reading frames of $1233 \mathrm{bp}$ coding for a 411 -amino acid protein. BLASTX searches with PcLFY against public database identified a group of highly similar proteins, including PRFLL and NLY from radiata pine (Mouradov et al., 1998; Mellerowics et al., 1998), an LFY-like sequence of Populus balsamifera (L.) (U 93196), NFL1 and NFL2 from Nicotiana tabacum (L.) (Kelly et al., 1995), LFY from $A$. thaliana (Weigel et al., 1992), FLO from Antirrhinum majus (Coen et al., 1990), and BOFH from Brassica oleracea (L.) (Anthony et al., 1993). Some other gymnosperm sequences were also retrieved from the databases and from published work (Frohlich and Parker, 2000). Alignments of the deduced amino acid sequence of PcLFY and other LFY-like proteins revealed that PcLFY shared with these sequences two major regions of conservation: amino acids $61-126$ and amino acids $247-406$ (50\% and $81 \%$ identity, and $75 \%$ and 
$88 \%$ similarity, respectively, to the LFY protein). It also had short regions of local similarity (Figure 2). The overall resemblance to the LFY protein was 53\% identity and 58\% similarity. The overall resemblance to the NLY and PRFLL protein was $72 \%$ identity and $94 \%$ similarity. Despite these similarities, the $P$. caribaea LFY-like protein clearly differed from its angiosperm counterparts. All pine sequences (PcLFY, PRFLL and NLY) had fewer proline residues in their proline-rich region (ca. first 40 amino acids) than any of the angiosperm proteins. The acidic region composed primarily of glutamic acid (E) and aspartic acid (D) residues (amino acids 207-219 of the LFY protein) was absent in pine. The less conserved 5' region was longer and the more conserved 3' region was shorter in pine species when compared to angiosperms.

\section{Evolutionary relationships}

A maximum parsimony consensus tree was constructed to access the phylogenetic relationships of PcLFY with its other gymnosperm and angiosperm counterparts (Figure 3). PcLFY is closely related to P. radiata PRFLL, but the distance between PcLFY and NLY exceeded the distance between most divergent angiosperm LFY orthologs. PcLFY was slightly closer to angiosperm proteins than NLY (distances 60-69\% vs. 64-72\%). When we considered only the gymnosperm LFY-like homologs, it became apparent that the gymnosperm sequences formed two groups: one containing NLY, and the other containing PcLFY and PRFLL. The phylogenetic relations of PcLFY with other plant LFY-related proteins revealed three facts. First, the gymnosperm sequences formed a group distinct from angiosperms. Second, the sequences of PcLFY and NLY were more divergent than any two angiosperm LFY orthologs. Third, the gymnosperm sequences formed two groups, named LFY-like and NLY-like. The mostly male theory of the origin of angiosperm flowers (Frohlich, 2003) assumes that the co-expression of genes responsible for the identity of male and female organs in a same structure would be sufficient to produce bisexual flowers in the angiosperm ancestor. Thus, the presence of two homologs of LFY in gymnosperms and of only one in most angiosperms (probably due to the loss of the NLY-like lineage) would be

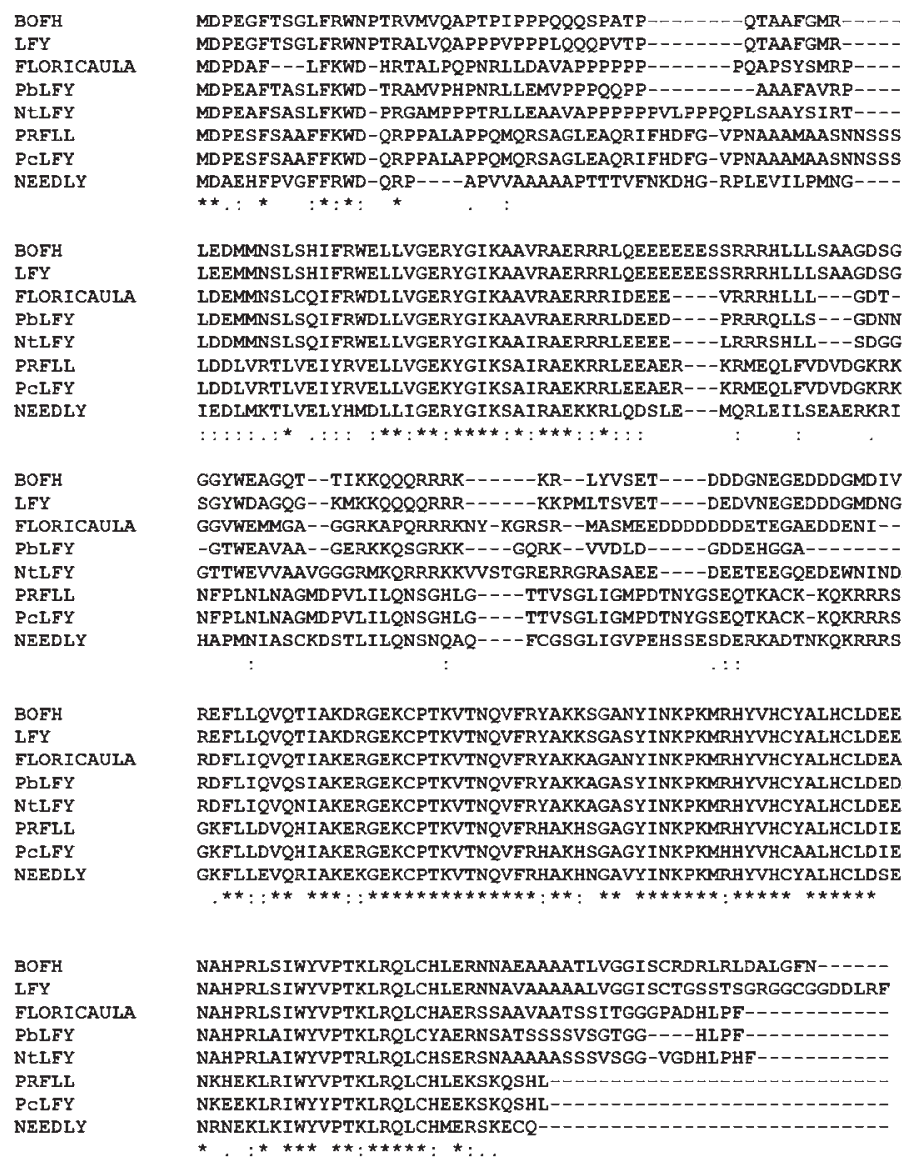

Figure 2 - Alignment of deduced amino acid LFY-like complete sequences with PcLFY. Sequences include: NEEDLY and PRFLL from radiata pine (Mouradov et al., 1998; Mellerowicz et al., 1998); PbLEAFY: LFY-like protein of Populus balsamifera (GenBank accession number U93196); NtLFY from Nicotiana tabacum (Kelly et al., 1995); Leafy from Arabidopsis thaliana (Weigel et al., 1992); FLO from Antirrhinum majus (Coen et al., 1990), BOFH from Brassica oleracea (Anthony et al., 1993). Identical residues are marked by asterisks, similar residues are marked by dots, gaps are marked by dashes. 


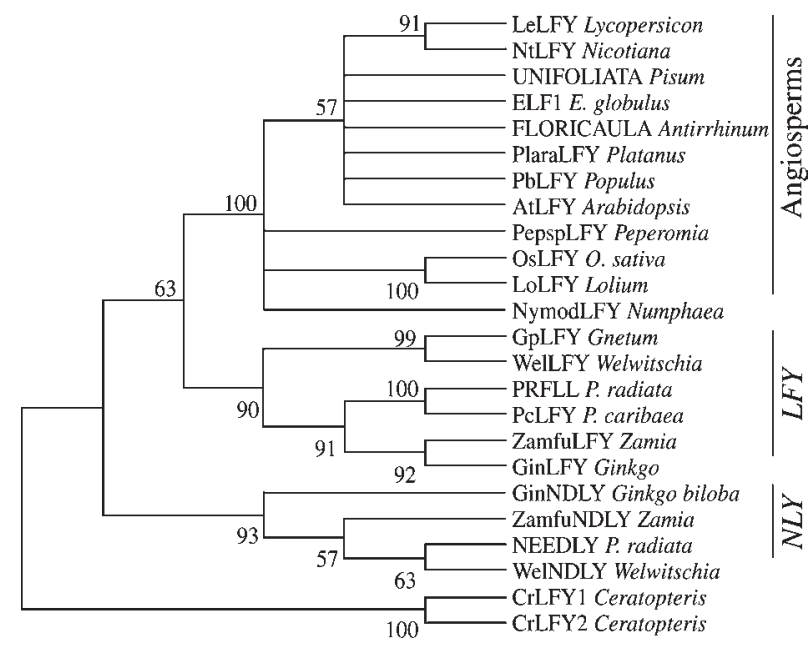

Figure 3 - Maximum parsimony consensus tree, built with the PAUP program, of deduced amino acid sequences of the complete LFY-like proteins. Numbers above the nodes indicate percent of trees with each node in a bootstrap analysis of 1000 random trees. Only the nodes present in $50 \%$ or more trees are drawn.

a key observation to corroborate the mostly male theory (Frohlich and Parker, 2000; Frohlich, 2003)

\section{Gene copy number determination and expression analyses}

To establish whether the PcLFY gene is a single-copy gene or part of a multigene family, we performed Southern Blot hybridization using digested $P$. caribaea genomic DNA. The hybridization pattern obtained using low stringency washes $\left(2 \mathrm{xSSC}, 42^{\circ} \mathrm{C}\right)$ suggested that an additional $P C L F Y$-like gene may exist in the $P$. caribaea genome (Figure 4A). However, using more stringent washes (i.e., $0.1 \mathrm{x}$ $\mathrm{SSC}, 65^{\circ} \mathrm{C}$ ), a single band was detected in each lane (data not shown). We also used the higher stringent conditions (i.e., $0.1 \times \mathrm{SSC}, 65^{\circ} \mathrm{C}$ ) to perform a Northern Blot analysis (Figure 4B), aiming to determine the steady-state PcLFY mRNA level in vegetative and reproductive tissues of $P$. caribaea. A single band corresponding to the transcript size of about $1.5 \mathrm{~kb}$ was observed, predominantly in developing female cones. This size corresponded to the cloned cDNA size and the transcript size of angiosperm $L F Y$ orthologs (Coen et al., 1990; Weigel et al., 1992; Kelly et al., 1995; Anthony et al., 1993).

The ontogenetic pattern of PcLFY expression was further studied by in situ hybridization, in longitudinal sections of shoot apices of adult (15 years-old) plants (Figure 5). Low levels of the PcLFY transcript were found in all types of meristems, but the hybridization signals were higher in developing female cones (Figure 5). With the Northern hybridization analysis, where the level of steadystate RNA was much lower in developing male cones and vegetative buds than in the developing female cones, some degree of expression was observed in vegetative tissues and male cones by in situ hybridization. The reason for that was
A

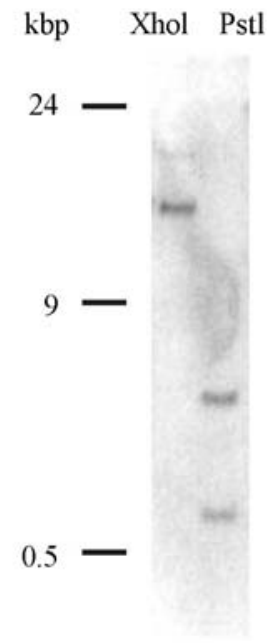

B

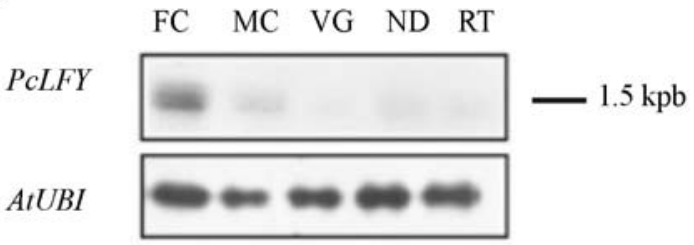

Figure 4 - A. Southern blot of genomic DNA from $P$. caribaea var. caribaea probed with PCLFY. Lane 1: digested with XhoI; lane:, digested with PstI. B. Northern blot made with total RNA extracted from developing female cones (FC), developing male cones (MC), vegetative apices of juvenile plants (VG), young leaves (needles) of adult plants (ND), and seedling roots (RT), probed with $P c L F Y$. The same blot was re-probed at low stringency with a heterologous Arabidopsis ubiquitin sequence (AtUBI) to show uniform loading and transfer of all lane contents.

probably a dilution of the peripheral bud tissues by very large pith and vascular tissue in the dominant mature buds, or maybe the probe and the stringency used in the hybridizations were not specific enough. No PcLFY transcript was detected in differentiating bracts or needles.

\section{Complementation of Arabidopsis Ify mutants by the expression of $P C L F Y$}

The coding region of the PCLFY cDNA was fused downstream to the Arabidopsis $L F Y$ promoter and used to transform Arabidopsis plants that were crossed to the strong-phenotype lfy-26 Arabidopsis mutant. Upon identification of homozygous transgenic mutant plants (verified by CAPs genotyping, data not shown, Konieczny and Ausubel, 1993), their phenotype was analyzed. Complete restoration of the wild-type phenotype was observed (Figure 6). Early-arising (basal) flowers were replaced by bracts with secondary inflorescence shoots in the Arabidopsis lfy-26 mutants, whereas later arising flowers were replaced by small bracts, in whose axils abnormal flowers developed (Figure 6B and C; Weigel et al., 1992). These abnormal flowers contained sepals and carpels but 

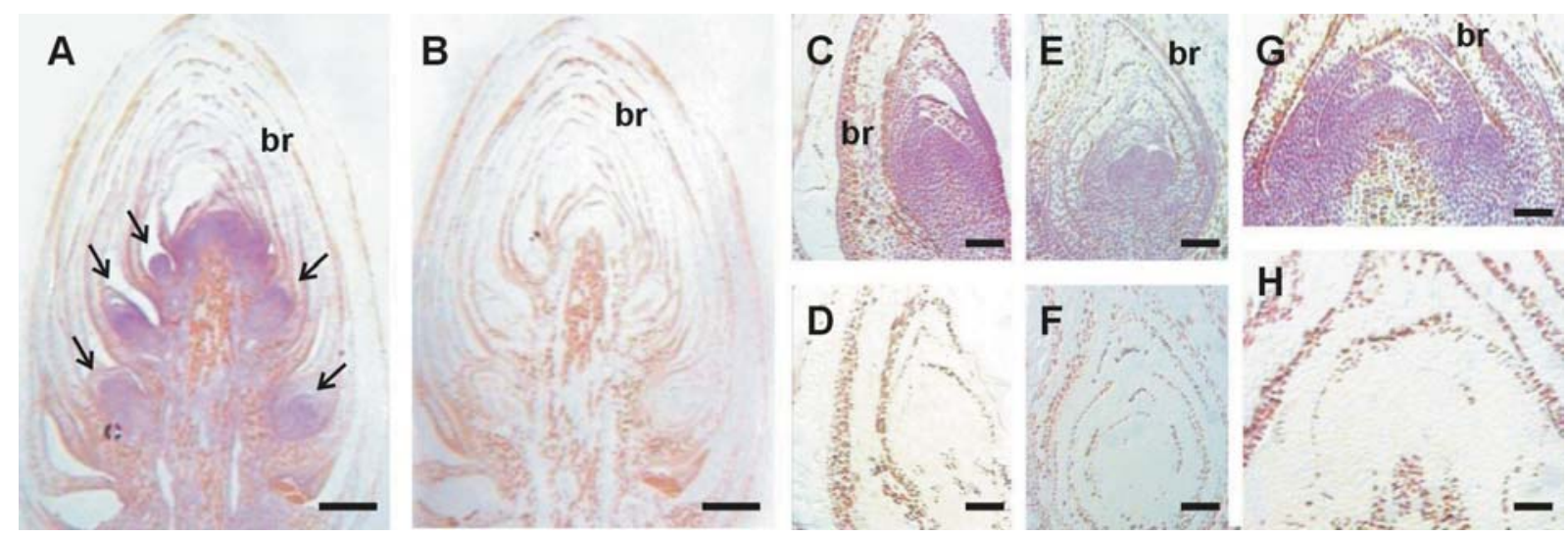

Figure 5 - In situ localization of $P c F Y$ transcripts. All sections are longitudinal. The pink-purple color indicates the hybridization signal. Hybridizations were performed with an antisense probe in A, C, E and G. In B, D, F and H a sense probe was used. In this case, no hybridization signal was observed above background level. A and B: Long-branch apex during the initiation of axillary meristems (arrows) on the side of apical meristem; C and D: developing short-branch female cone with initiating bract primordia (br). E and F: developing short-branch male cone with initiating bract primordia (br). G and $\mathrm{H}$ : Detail of an apical meristem of an adult (15 years-old) plant. Bars: A and B: $600 \mu \mathrm{m}$; C-F: $250 \mu \mathrm{m} ; \mathrm{G}$ and $\mathrm{H}: 100 \mu \mathrm{m}$.
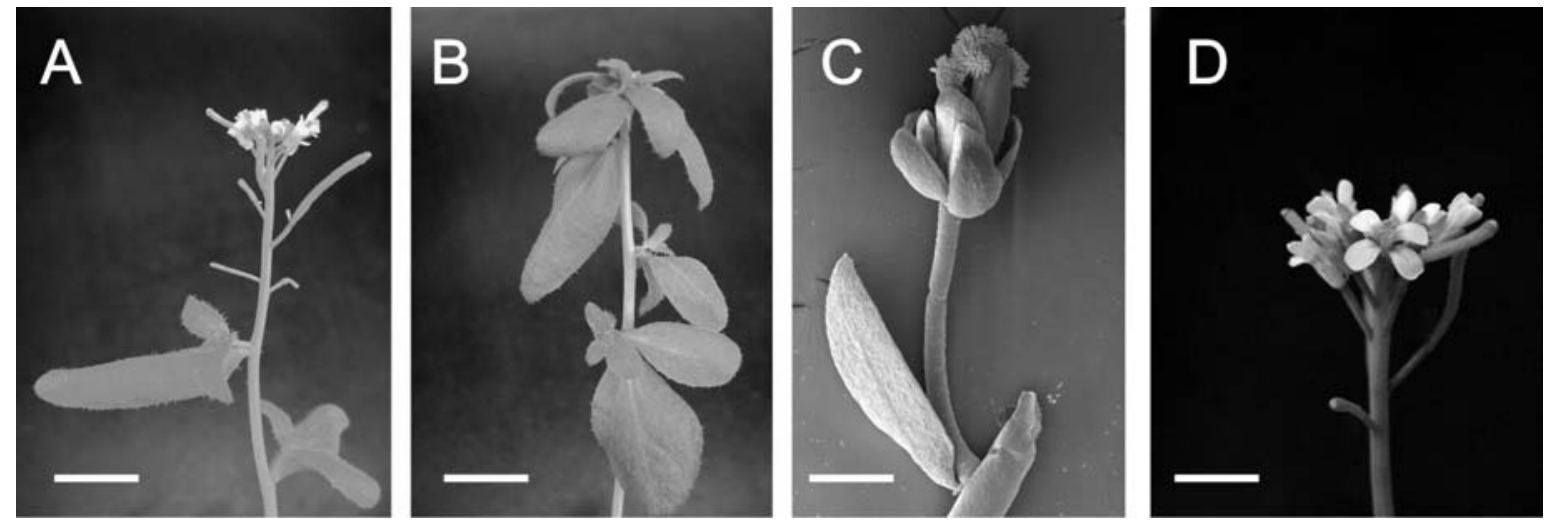

Figure 6 - The $P C L F Y$ expression driven by the $L F Y$ promoter can complement an Arabidopsis strong lfy mutation. A: wild-type inflorescence (Columbia ecotype) showing flower buds at different developmental stages. B: main inflorescence axis of an $l f y-26$ mutant. Solitary flowers are replaced by a cauline leaf (bract) adjacent to a lateral inflorescence axis or an abnormal flower. C: SEM image of an abnormal flower of the lfy-26 mutant. Note the cauline leaf and the homeotic conversion of petals and stamens in sepal-like organs and carpel-like organs, respectively. D: A homozygous transgenic (LFY::PcLFY) $l f y$-26 mutant showing a wild-type phenotype, indicating the complementation of the lfy mutation by the expression of PcLFY. Bars: A and B: $6 \mathrm{~mm}$; C: $400 \mu \mathrm{m} ; \mathrm{D}: 3 \mathrm{~mm}$.

no petals or stamens, these later being usually homeotically substituted by more sepals and carpels, respectively (Figure 6C; Weigel et al., 1992). In contrast, wild-type flowers typically contain four sepals, four petals, six stamens and two carpels. The lfy-26 floral phenotype was largely complemented by the $L F Y:: P c L F Y$ transgene. The main shoot of these plants developed flowers in both basal and apical positions, and most of these contained all four floral organ types (Figure 6D).

\section{Discussion}

The LFY homologs have been consistently reported to be involved in flower formation in angiosperms (Lohmann and Weigel, 2002). The existence of its homologs in pre-angiosperm plant species that do not form flowers was confirmed by cloning of cDNAs from some gymnosperm species (Mouradov et al., 1998; Mellerowicz et al., 1998; Frohlich and Parker, 2000). Phylogenetic analysis (Figure 3) has demonstrated that gymnosperm sequences form a separate clade from angiosperms and that gymnosperms have, in contrast to angiosperms (Kelly et al., 1995), two paralogous genes resembling FLO/LFY (see also Frohlich and Parker, 2000). These two genes, represented by $P C L F Y$ and $N L Y$, had rather divergent sequences, yet they shared some features that distinguished them from their angiosperm counterparts. The existence of two divergent $L F Y$-related gene lineages in gymnosperms and the presumptive loss of one of these lineages in angiosperms may be one of the causative forces of the origin of bisexual flowers in angiosperms (Frohlich, 2003). Proline-rich and acidic domains in LFY and FLO (Coen et al., 1990; Weigel et al., 1992), whose presence indicates that these proteins 
are transcription factors, were not evident in conifers (Figure 2). In contrast, the $\mathrm{C}$-terminal part of the protein, whose function has not been elucidated so far, was highly conserved between angiosperms and conifers. The significance of differences between angiosperms and conifers will become clear when the LFY protein is functionally analyzed by deletion and domain-swamping experiments.

As in angiosperm species, $P C L F Y$ was preferentially expressed in reproductive tissues and was not detected in fully differentiated vegetative tissues (Figures 4B and 5; Kelly et al., 1995; Anthony et al., 1993) Mouradov et al. (1998) have shown that $N L Y$ was highly expressed only in the very early developing female reproductive structures, before any specifically female attributes have arisen. In contrast, Mellerowicz et al. (1998) reported the expression of PRFLL in vegetative buds and in the early stages of the male reproductive cone. Thus, the PCLFY expression pattern may be considered intermediary between the $N L Y$ and PRFLL expression patterns, as it is expressed in the early stages of the female reproductive cone as well as in the vegetative buds (Figures 4B and 5). The published data on ontogenetic changes in $L F Y$ expression in vegetative meristems of Arabidopsis are contradictory (Blázquez et al., 1997; Hempel et al., 1997), indicating that factors other than maturation affect the level of expression more directly.

The biological role of the expression of PCLFY or angiosperm $L F Y$ orthologs in vegetative buds is still unclear. Whereas neither lesions in LFY or FLO (Coen et al., 1990; Huala and Sussex, 1992; Weigel et al., 1992) nor ectopic over-expression of $L F Y$ (Weigel and Nilsson, 1995; Nilsson and Weigel, 1997) affected vegetative development in several angiosperms, it might not be the case in more primitive species. If the flower is homologous to an entire shoot of a cordaite-like progenitor (Hickey and Taylor, 1996), LFY function might have evolved from a gene that controls some aspects of shoot development, for example cell determinacy (Kelly et al., 1995; Hofer et al., 1997). Regardless of the ground level of $L F Y$ expression, floral stimulus, be it photoperiod, far-red light treatments, or gibberellin application, was reported to rapidly up-regulate the expression of this gene in diverse angiosperms (Coen et al., 1990; Weigel et al., 1992; Carpenter et al., 1995; Anthony et al., 1993; Blázquez et al., 1997; Hempel et al., 1997). The up-regulation preceded the attainment of developmental commitment to flower (Hempel et al., 1997), and the level of LFY activity determined how rapidly plants started producing flowers (Blázquez et al., 1997). These data are consistent with LFY being a necessary and quantitative, but not always sufficient, factor of floral determination. Our observations of high PcLFY expression in buds with undifferentiated, and therefore possibly not determined, female cone primordia is consistent with PcLFY playing an analogous role in the determination of the female cone primordium identity. In contrast, PcLFY does complement the defects observed in male reproductive de- velopment in Arabidopsis lfy-26 mutants (Figure 6). It is thus tempting to speculate that two LFY-like conifer paralogs represented by PcLFY and NLY have separate roles in the reproductive determination of separate male and female reproductive organs. Unlike unisexual angiosperm flowers that have a perfect flower ancestry, conifer cones evolved as truly unisexual organs. It is conceivable that separate meristem identity genes were involved in the determination of male and female organs, and that the function of female organ determination became redundant when the perfect flower evolved. Future comparative in situ-expression studies, analysis of transgenic plants, and studies of a broad range of pre-angiosperm species are likely to resolve these questions.

\section{Acknowledgments}

The authors wish to thank Weber A. Neves do Amaral (ESALQ/USP, Forestry Department) for great support on early stages of this work; F.C.A. Tavares and G. Bandel (ESALQ/USP, Genetics Department) for providing an excellent research environment; E.W. Kitajima for maintaining the scanning electron microscope facility at NAP/ MEPA (University of São Paulo, ESALQ, Piracicaba, Brazil); TAIR and the Ohio State University for the Arabidopsis seed stock maintenance; D. Weigel (Salk Institute, La Jolla, USA) for the generous gifts of plasmids pDW124, pDW132 and pSKI015. MCD is grateful to the Fundação de Amparo à Pesquisa do Estado de São Paulo (FAPESP) for financial support. APMR acknowledges the support of CNPq by means of a research fellowship.

\section{References}

Altschul J, Madden TL, Schffer AA, Zhang J, Zhang Z, Miler W and Lipman DJ (1997) Gapped BLAST and PSI-BLAST: A new generation of protein database search programs. Nucl Acids Res 25:3389-3402.

An G, Chung YY, Kim SR, Kang HG and Gupta HS (1994) MADS box genes in rice. Flowering Newslett 18:33-37.

Anthony RG, James PE and Jordan BR (1993) Cloning and sequence analysis of a flo/lfy homologue isolated from cauliflower (Brassica oleracea L. var. botrytis). Plant Mol Biol 22:1163-1166.

Bechtold N and Pelletier G (1998) In planta Agrobacterium mediated transformation of adult Arabidopsis thaliana plants by vacuum infiltration. Methods Mol Biol 82:259-266.

Blázquez MA, Soowal LN, Lee I and Weigel D (1997) Leafy expression and flower formation in Arabidopsis. Development 124:3835-3844.

Bollman MP (1983) Morphology of long-shoot development in Pinus radiata. N Z J For Sci 13:275-290.

Carpenter R, Copsey L, Vincent C, Doyle S, Magrath R and Coen E (1995) Control of flower development and phyllotaxy by meristem identity genes in antirrhinum. Plant Cell 7:20012111.

Cecich RA, Kang H and Chalupka W (1994) Regulation of early flowering in Pinus banksiana. Tree Physiol 14:275-284. 
Coen ES, Romero JM, Doyle S, Elliott R, Murphy G and Carpenter R (1990) Floricaula: A homeotic gene required for flower development in Antirrhinum majus. Cell 63:1311-1322.

Colombo L, Busscher M, Franken J and Angenent GC (1996) MADS box genes controlling flower development in Petunia. Flowering Newslett 22:13-19.

Doak CC (1935) Evolution of foliar types, dwarf shoots, and cone scales of Pinus. Univ Illinois Bull 32:127-230.

Dornelas MC, Van Lammeren AA and Kreis M (2000) Arabidopsis thaliana SHAGGY-related protein kinases (AtSK11 and 12) function in perianth and gynoecium development. Plant J 21:419-429.

Dornelas MC, Wittich PE, von Recklinghausen IR, van Lammeren AAM and Kreis M (1999) Characterization of three novel members of the Arabidopsis SHAGGY-related protein kinases (ASK) multigene family. Plant Molecular Biology 39:137-147.

Dornelas MC, Vieira MLC and Appezzato-da-Glória B (1992) Histological analysis of organogenesis and somatic embryogenesis induced in immature tissues of Stylosanthes scabra. Ann Bot 70:477-482.

Frohlich MW (2003) An evolutionary scenario for the origin of flowers. Nature Reviews Genetics 4:559-566.

Frohlich MW and Meyerowitz EM (1997) The search for homeotic gene homologs in basal angiosperms and Gnetales: A potential new source of data on the evolutionary origin of flowers. Int J Plant Sci 158:S131-S142.

Frohlich MW and Parker DS (2000) The mostly male theory of flower evolution origins: From genes to fossils. Syst Bot 25:155-170.

Hempel FD, Weigel D, Mandel MA, Ditta G, Zambryski PC, Feldman LJ and Yanofsky MF (1997) Floral determination and expression of floral regulatory genes in Arabidopsis. Development 124:3845-3853.

Hickey LJ and Taylor DW (1996) Origin of the angiosperm flower. In: Taylor DW and Hickey LJ (eds) Flowering Plant Origin, Evolution \& Phylogeny. Chapman \& Hall, New York, pp 176-231.

Hofer J, Turner L, Hellens R, Ambrose M, Mathews P, Michael A and Ellis N (1997) Unifoliata regulates leaf and flower morphogenesis in pea. Curr Biol 7:581-587.

Huala E and Sussex IM (1992) Leafy interacts with floral homeotic genes to regulate Arabidopsis floral development. Plant Cell 4:910-913.

Izawa T, Takahashi Y and Yano M (2003) Comparative biology comes into bloom: Genomic and genetic comparison of flowering pathways in rice and Arabidopsis. Curr Opin Plant Biol 6:113-120.

Kelly AJ, Bonnlander MB and Meeks-Wagner DR (1995) NFL, the tobacco homolog of Floricaula and Leafy, is transcriptionally expressed in both vegetative and floral meristems. Plant Cell 7:225-234.

Konieczny A and Ausubel FM (1993) A procedure for mapping Arabidopsis mutations using co-dominant ecotype-specific PCR-based markers. Plant J 4:403-410.

Levy YY and Dean C (1998) The transition to flowering. Plant Cell 10:1973-1989.

Lohmann JU and Weigel D (2002) Building beauty: The genetic control of floral patterning. Developmental Cell 2:135-142.
Mena M, Ambrose BA, Meeley RB, Briggs SP, Yanofsky MF and Schmidt RJ (1996) Diversification of C-function activity in maize flower development. Science 274:1537-1540.

Mellerowicz EJ, Horgan K, Walden A, Coker A and Walter C (1998) PRFLL: A Pinus radiata homologue of Floricaula and Leafy is expressed in buds containing vegetative and undifferentiated male cone primordia. Planta 206:619-629.

Mouradov A, Glassic T, Hamdorf B, Murphy L, Fowler B, Marla $\mathrm{S}$ and Teasdale RD (1998) NEEDLY, a Pinus radiata ortholog of Floricaula/Leafy genes, expressed in both reproductive and vegetative meristems. Proc Natl Acad Sci USA 95:6537-6542.

Münster T, Pahnke J, Di Rosa A, Kim JT, Martin W and Saedler H (1997) Floral homeotic genes were recruited from homologous MADS-box genes preexisting in the common ancestor of ferns and seed plants. Proc Natl Acad Sci USA 94:24152420 .

Nilsson O and Weigel D (1997) Modulating the timing of flowering. Curr Opin Biotech 8:195-199.

Page RDM(2000) TreeView software, version 1.6.1, http://taxonomy.zooology.gla.ac.uk/rod/rod.html.

Pnuelli L, Hareven D, Rounsley SD and Yanofsky MF (1994) Isolation of the tomato Agamous gene TAG1 and analysis of its homeotic role in transgenic plants. Plant Cell 6:163-173.

Riding RT (1972) Early ontogeny of seedlings of Pinus radiata. Can J Bot 50:2381-2387.

Sambrook J, Fritsch FP and Maniatis T (1989) Molecular Cloning: A Laboratoty Manual. 2nd ed. Cold Spring Harbour Laboratory Press, Cold Spring Harbour, NY, pp 2.60-2.80.

Sussman MR, Amasino RM, Young JC, Krysan PJ and Austin-Phillips S (2000) The Arabidopsis knock-out facility at the University of Wisconsin-Madison. Plant Physiol 124:1465-1467.

Swofford DL (1998) PAUP: Phylogenetic analysis using parsimony. Version 4. Sinauer Associates, Sunderland, Massachusetts, USA.

Tandre K, Albert VA, Sundas A and Engstrom P (1995) Conifer homologues to genes that control floral development in angiosperms. Plant Mol Biol 27:69-78.

Thompson JD, Higgins DG and Gibson TJ (1994) Clustal W: Improving the sensitivity of progressive multiple sequence alignment through sequence weighting, positions-specific gap penalties and weight matrix choice. Nucleic Acids Res 22:4673-4680.

Walter C, Grace LJ, Wagner A, White DWR, Walden AR, Donaldson SS, Hinton H, Gardner RC and Smith DR (1998) Stable transformation and regeneration of transgenic plants of Pinus radiata D. Don. Plant Cell Rep 17:460-468.

Weigel D and Nilsson O (1995) A developmental switch sufficient for flower initiation in diverse plants. Nature 377:495500.

Weigel D, Alvarez J, Smyth DR, Yanofsky MF and Meyerowitz EM (1992) Leafy controls floral meristem identity in Arabidopsis. Cell 69:843-859.

Zhu KY and Clark JM (1995) Rapid construction of nested deletions of recombinant plasmid DNA for dideoxy sequencing. Biotechniques 18:222-224. 